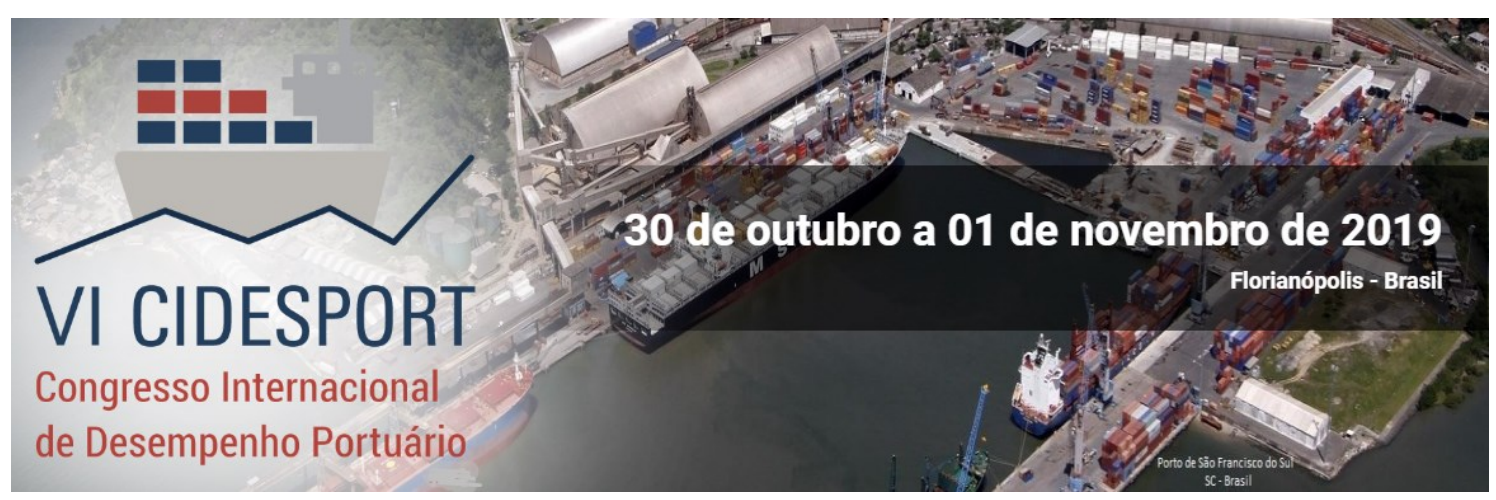

\title{
CUSTO LOGÍSTICO DO TRANSPORTE RODOVIÁRIO ENTRE AS REGIÕES PRODUTORAS E OS PRINCIPAIS PORTOS E TERMINAIS PRIVADOS EXPORTADORES DE GRÃOS AGRÍCOLAS DO SUL E SUDESTE BRASILEIRO
}

\section{Elivelton Dore \\ SCpar Porto de Imbituba}

\section{Murilo da Silva de Medeiros \\ SCpar Porto de Imbituba}

Resumo: O presente artigo científico visou contabilizar o custo logístico médio no transporte rodoviário entre as regiões produtoras e os principais portos e terminais exportadores de grãos agrícolas do Sul e Sudeste do Brasil. Para tanto, levantouse a produção de grãos agrícolas no Brasil em escala nacional, estadual e mesorregional; identificaram-se as distâncias rodoviárias entre as principais regiões produtoras e os principais portos exportadores de grãos agrícolas das regiões Sul e Sudeste e calculou-se o custo logístico médio no transporte rodoviário entre as regiões produtoras e os principais portos exportadores de grãos do Sul e Sudeste. Metodologicamente, tratou-se de uma pesquisa de levantamento, exploratória e quantitativa. Como principais resultados, atestou-se que o menor custo logístico rodoviário para transportar as mercadorias do Noroeste Gaúcho, uma das regiões líderes na produção de grãos, é o Porto de Imbituba, em Santa Catarina, e do Norte Mato-Grossense, outra região líder, é o Porto de Santos, em São Paulo. Concluiuse, assim, que a contabilização do custo logístico rodoviário se constitui enquanto uma etapa de um processo maior de contabilização dos custos logísticos totais que, se estudados conjuntamente a outras macrovariáveis impactantes no processo de tomada da decisão de movimentar por este ou aquele porto ou terminal de uso privado, podem assumir destacada importância.

Palavras chave: Setor Portuário. Logística. Grãos. Transporte. Agricultura.

\section{INTRODUÇÃO}

A globalização é um processo contínuo que se intensifica a cada dia. Inserirse nas cadeias globais de produção provenientes do mundo globalizado, assim, é imprescindível para a sustentabilidade econômica de um país. Exportar, nesse sentido, é uma das atividades econômicas de maior importância. Nas palavras de Minervini (2008), exportar é bom para as empresas, para seus colaboradores, para os empresários, para a cidade, para a região, para o estado e para o país, num todo.

Em termos de exportação, os grãos agrícolas ganham destaque em nosso país. O Brasil é conhecido mundialmente como um dos principais produtores primários do planeta, em especial no que tange aos grãos, destacando-se principalmente na produção de milho, soja, arroz e outros. Sendo assim, ao tratar desse tema, o presente trabalho está atualizado no que toca aos assuntos de

\footnotetext{
* A revisão gramatical, ortográfica, ABNT ou APA foi realizada pelos autores.
} 
relevância à economia nacional, buscando realizar proposições dentro do escopo abordado com vistas a possibilitar uma maior qualificação e desenvolvimento da economia nacional.

Além disso, isso se torna ainda mais estratégico quando se insere a cadeia logística e seus custos na discussão. Desenvolver-se economicamente depende de crescimento econômico e este das exportações que, por sua vez, dependem da produção. As zonas responsáveis pela produção agrícola e pela exportação efetiva, isto é, principalmente as áreas portuárias nacionais, quase nunca se encontram no mesmo espaço ou relativamente próximas. Existe uma estratégia logística e todos os seus desafios para que os produtos primários cheguem até os portos nacionais. Alternativas, propostas de qualificação e diminuição de custos para tais estratégias logísticas são, além de bem-vindas, imprescindíveis.

Entretanto, para que isso se viabilize, faz-se necessário clarificar quais os custos logísticos estão envoltos, de fato, na cadeia de transporte responsável por movimentar os grãos agrícolas até as zonas portuárias. E é por isso que o presente trabalho, ao tratar do custo logístico rodoviário e como se insere nessa cadeia logística maior, assume relativa relevância, uma vez que se constitui enquanto etapa importante para um grande projeto em torno de avaliações e proposições para a redução dos custos logísticos e o proporcionamento de uma maior competitividade para os grãos brasileiros e seus produtores. Além disso, existe cerca escassez no que toca ao tema na literatura logística nacional.

É nesse sentido que, a partir dos argumentos anteriormente elucidados, apresenta-se enquanto problema central deste trabalho o seguinte: qual o custo logístico médio do transporte rodoviário entre as regiões produtoras e os principais portos e terminais exportadores de grãos agrícolas do Sul e Sudeste do Brasil? Tendo isso em vista, o objetivo geral proposto é o seguinte: contabilizar o custo logístico médio no transporte rodoviário entre as regiões produtoras e os principais portos e terminais exportadores de grãos agrícolas do Sul e Sudeste do Brasil. Para tanto, os seguintes objetivos específicos foram necessários: a) levantar a produção de grãos agrícolas no Brasil em escala nacional, estadual e mesorregional, b) identificar as distâncias rodoviárias entre as principais regiões produtoras e os principais portos exportadores de grãos agrícolas das regiões Sul e Sudeste e c) calcular o custo logístico médio no transporte rodoviário entre as regiões produtoras e os principais portos exportadores de grãos do Sul e Sudeste.

\section{REFERENCIAL TEÓRICO}

Com o significativo aumento da competitividade que vem ocorrendo na maioria dos mercados, sejam industriais, comerciais ou prestação de serviços, os custos tornam-se altamente relevantes quando da tomada de decisões em uma empresa. Isto ocorre pois, devido à alta competição existente, as empresas já não podem mais definir seus preços apenas de acordo com os custos incorridos, e sim, também, com base nos preços praticados no mercado em que atuam (MARTINS, Eliseu, 2018).

O transporte de cargas, além de contribuir para o aumento do comércio entre as nações, também é um dos componentes relevantes pelos custos finais dos produtos. Para que haja eficácia no controle dos custos finais dos produtos visando sua maior competitividade, o gerenciamento da cadeia de suprimentos deve ser dirigido de forma a administrar os custos logísticos de forma eficiente (FLORENTINO, Mauro Silva, 2010). 
De acordo com Ballou (2006), o transporte representa o elemento mais importante da logística. Com um sistema de transportes precariamente desenvolvido, a extensão do mercado fica limitada àquelas áreas imediatamente próximas ao ponto de produção. Complementa Keedi (2001), dizendo que para a criação e desenvolvimento da logística adequada é fundamental o conhecimento dos vários modais de transporte, bem como as cargas adequadas a cada um deles (PONTES et al, 2009).

Conforme Batalha et al (1997), o Estado assume o papel de provedor da infraestrutura logística, sendo assim, responsável por um componente relevante dos custos das empresas. Em um contexto de comércio internacional, essa infraestrutura é especialmente relevante porque determina os custos com que as mercadorias de um país chegam ao mercador externo. Um sistema logístico mais eficiente pode, portanto, reduzir os custos das mercadorias que um país coloca no mercado internacional. Em outras palavras, o sistema logístico é um fator de competitividade no mercado internacional, substituindo estratégias tradicionais e repletas de consequências negativas, como a desvalorização cambial.

É imperioso destacar que as ferrovias e hidrovias representam grande redução de custos no deslocamento das riquezas, entretanto, mesmo com as dimensões continentais existentes no país, o modal de transporte rodoviário é um dos principais destaques no escoamento da produção agrícola nacional. De acordo com a Confederação Nacional do Transporte, no ano de 2017, cerca de $61 \%$ do transporte de cargas no Brasil foi feito através do modal rodoviário, sendo ferroviário e hidroviário responsáveis por $20,7 \%$ e $13,6 \%$, respectivamente. Nota-se uma grande dependência do transporte rodoviário em relação às commodities agrícolas (REIS et al, 2008).

No Brasil, um gargalo visível de produtos agrícolas para exportação está relacionado à logística. Sabe-se que o transporte precário da matéria-prima entre as fontes primárias de produção para a exportação, representa enorme prejuízo para o país. A melhoria das rodovias e do modal ferroviário e o melhor aproveitamento do transporte hidroviário são essenciais e prementes, além do aperfeiçoamento da produtividade dos portos e armazéns. O Brasil perde a competitividade quando o produto agrícola sai pela porteira das propriedades rurais com preços baixos e chega ao destino com custos altíssimos por causa dos problemas logísticos (OMETTO, 2006).

Segundo Paduan (2005), as empresas brasileiras perdem 10 bilhões por ano em razão dos gargalos logísticos do país. Essa perda significa menos produtividade e, portanto, menos atividades econômicas. Complementa Chernij (2005) dizendo que os custos logísticos no Brasil ficam em torno de $17 \%$ do PIB, enquanto nos EUA não passa de $9 \%$. No ano de 2005 , aproximadamente 200 empresas brasileiras saíram do comércio exterior devido aos altos custos logísticos brasileiros. (PONTES et al, 2009).

Nesse sentido, os custos envolvidos no transporte rodoviário para escoar os grãos agrícolas aos portos brasileiros torna-se parcela relevante de custo de toda cadeia logística de distribuição destes itens ao mercado internacional, fazendo com que o emprésário realize um planejamento adequado de sua rota logística até os principais portos brasileiros, evitando desperdícios, gerando maior competitividade e maximizando seus lucros.

\section{PROCEDIMENTOS METODOLÓGICOS}


Do ponto de vista de sua natureza, esta pesquisa trata-se de uma pesquisa aplicada, uma vez que visou a gerar informações com o intuito de serem utilizadas para finalidades imediatas no tocante ao processo de decisão em relação a que porto ou terminal de uso privado escolher para exportação dos grãos agrícolas. Vergara (2000, p. 47) define a pesquisa aplicada como sendo "fundamentalmente motivada pela necessidade de resolver problemas concretos, mais imediatos ou não".

Já do ponto de vista da abordagem do problema, a pesquisa se classifica enquanto quantitativa, uma vez que se utiliza de parâmetros, sobretudo, estatísticos em sua tratativa.

Do ponto de vista de seus objetivos, trata-se de uma pesquisa descritiva, já que não se limita a tratar o objeto de forma exploratória, mas também não avança ao ponto de realizar uma análise aos moldes de uma pesquisa explicativa, focandose no trabalho com as estatísticas geradas e estudadas. Vergara $(2000$, p.47) argumenta que a pesquisa descritiva expõe as características de determinada população ou fenômeno, estabelece correlações entre variáveis e define sua natureza.

Por fim, no que toca aos procedimentos técnicos para a coleta de dados, trata-se de uma pesquisa de levantamento, uma vez que envolveu o levantamento de dados numéricos específicos referentes ao tema em questão.

A pesquisa, de forma geral, se deu em quatro etapas, sendo que as três primeiras traduziram-se enquanto a busca pelo alcance dos objetivos específicos elucidados e a quarta se tratando de uma proposição que foi além do escopo do trabalho, abrindo caminho para avanços em sua tratativa.

A primeira etapa consiste no levantamento da produção agrícola nacional para identificar as principais regiões produtoras do país, etapa seguinte consiste na identificação das distâncias entre os principais portos da região sul e sudeste brasileiro e as regiões de maior produção encontrada na primeira etapa, concluído com a terceira etapa que verifica o custo por tonelada transportada de grãos agrícolas aos principais portos e terminais do Já a terceira etapa sul e sudeste do país.

A quarta e última etapa consiste na análise da movimentação portuária nos portos identificados e sua eficiência operacional para escoar a produção agrícola ao exterior.

\section{RESULTADOS}

A primeira fase da presente pesquisa consiste na identificação dos elementos necessários para definir o custo logístico rodoviário para o transporte dos grãos agrícolas até os principais portos do sul e sudeste brasileiro primeiro. Custo logístico pode ser interpretado como o desembolso necessário para colocar o produto a disposição de seu cliente, compreendendo o transporte, armazenagem e demais gastos necessários a entrega do produto. Na exportação de grãos agrícolas este se torna um dos principais custos agregados na venda desta mercadoria, devido ao seu baixo valor agregado.

\subsection{Levantamento da produção de grãos agrícolas}

Esta pesquisa buscou, inicialmente, levantar a produção de grãos agrícolas no Brasil em escala nacional, estadual e mesorregional. Para tanto, fez-se necessário identificar as principais regiões produtoras de grãos agrícolas no Brasil por meio de fontes de natureza confiável para dimensionar os referidos 
quantitativos. Anualmente, o Instituto Brasileiro de Geografia e Estatística investiga a produção agrícola das principais culturas do país, fonte de dados esta que servirá como direcionador para encontrar as principais regiões produtoras de grãos agrícolas brasileiras.

O IBGE é responsável por gerenciar o PAM - Produção Agrícola Municipal, o qual é um levantamento estatístico da produção integrado ao programa de Levantamento Sistemático da Produção Agrícola. Conforme o IBGE, o relatório da Produção Agrícola Municipal (PAM):

\begin{abstract}
Investiga um conjunto de produtos das lavouras temporárias e permanentes do País que se caracterizam não só pela grande importância econômica que possuem na pauta de exportações, como também por sua relevância social, componentes que são da cesta básica do brasileiro, tendo como unidade de coleta o município. A Produção Agrícola Municipal - PAM teve início no Ministério da Agricultura em 1938. Suas informações eram levantadas pela Rede de Coleta do IBGE, cabendo ao Ministério a elaboração dos questionários, a apuração, a crítica e a divulgação dos resultados. Com a publicação do Decreto n. 73.482 , de 17.01.1974, o Instituto tornou-se responsável por todas as fases da pesquisa a partir daquela data, bem como pelos demais inquéritos estatísticos relacionados ao setor agropecuário. (IBGE, 2018)
\end{abstract}

Foram utilizados os dados registrados no PAM durante o ano de 2016, aprovados e divulgados pelo IBGE. Procurou extrair as principais informações necessárias a pesquisa. A coleta de dados de produção agrícola através dos dados fornecidos pelo IBGE referentes ao PAM - Produção Agrícola Municipal no ano de 2016 são realizados por cidade, entretanto nesta pesquisa foram então agrupados a sua produção por regiões.

Quadro 1 - Produção do Brasil, por região, dos principais grãos agrícolas no ano de 2016, em toneladas ( $\mathrm{t}$ )

\begin{tabular}{|c|c|c|c|c|c|c|}
\hline Região ou Estado & Arroz & Milho & Soja & Trigo & TOTAL & $\%$ \\
\hline Norte & 925.072 & 1.886 .025 & 4.096 .882 & 0 & 6.907 .979 & $3,88 \%$ \\
\hline Nordeste & 271.226 & 3.161 .408 & 5.145 .197 & 19.800 & 8.597 .631 & $4,83 \%$ \\
\hline Sudeste & 77.490 & 10.481 .710 & 7.539 .366 & 580.443 & 18.679 .009 & $10,50 \%$ \\
\hline Sul & 8.663 .291 & 21.147 .414 & 35.374 .615 & 6.120 .603 & 71.305 .923 & $40,08 \%$ \\
\hline Centro-Oeste & 685.110 & 27.466 .857 & 44.140 .654 & 113.575 & 72.406 .196 & $40,70 \%$ \\
\hline TOTAL & $\mathbf{1 0 . 6 2 2 . 1 8 9}$ & $\mathbf{6 4 . 1 4 3 . 4 1 4}$ & $\mathbf{9 6 . 2 9 6 . 7 1 4}$ & $\mathbf{6 . 8 3 4 . 4 2 1}$ & $\mathbf{1 7 7 . 8 9 6 . 7 3 8}$ & $\mathbf{1 0 0 , 0 0 \%}$ \\
\hline
\end{tabular}

Fonte: Adaptado de IBGE (2016).

Nota-se que a região Centro-Oeste, junto á região Sul, são as regiões de maior produção de grãos agrícolas na esfera nacional. A primeira destaca-se na produção de milho e soja e a segunda na produção de arroz. Ao todo, ambas as regiões produzem mais de 140 milhões de toneladas ao ano, uma produção que representa $80,76 \%$ de toda a produção nacional.

Num segundo momento, identificado os principais estados produtores de grãos agrícolas, dividiu-se a produção pelas principais mesorregiões destes estados. Os dados coletados constam no quadro 02:

Quadro 2 - Produção brasileira, por mesorregiões dos estados ou estados, dos principais grãos agrícolas no ano de 2016, em toneladas ( $\mathrm{t}$ )

\begin{tabular}{|c|c|c|c|c|c|c|}
\hline $\begin{array}{c}\text { Mesorregião ou } \\
\text { estado }\end{array}$ & Arroz & Milho & Soja & Trigo & TOTAL & $\%$ \\
\hline Santa Catarina & $\mathbf{1 . 0 5 0 . 8 5 9}$ & $\mathbf{2 . 5 3 0 . 3 6 3}$ & $\mathbf{2 . 1 3 9 . 6 1 1}$ & $\mathbf{2 2 1 . 2 6 5}$ & $\mathbf{5 . 9 4 2 . 0 9 8}$ & $\mathbf{3 , 3 4 \%}$ \\
\hline Oeste & 315 & 1.521 .516 & 1.050 .827 & 116.813 & 2.689 .471 & $1,51 \%$ \\
\hline
\end{tabular}



de Desempenho Portuário

\begin{tabular}{|c|c|c|c|c|c|c|}
\hline Norte & 143.544 & 280.224 & 504.185 & 56.274 & 984.227 & $0,55 \%$ \\
\hline Serrana & 30 & 438.441 & 543.874 & 42.673 & 1.025 .018 & $0,58 \%$ \\
\hline Vale Itajaí & 208.929 & 170.501 & 39.807 & 5.361 & 424.598 & $0,24 \%$ \\
\hline Grande Florianopolis & 37.364 & 20.240 & 144 & 144 & 57.892 & $0,03 \%$ \\
\hline Sul & 660.677 & 99.441 & 774 & 0 & 760.892 & $0,43 \%$ \\
\hline Paraná & 119.001 & 13.887 .103 & 17.025 .112 & 3.357 .449 & 34.388 .665 & $19,33 \%$ \\
\hline Noroeste & 90.605 & 608.330 & 618.775 & 6.744 & 1.324 .454 & $0,74 \%$ \\
\hline Centro Ocidental & 283 & 1.734 .561 & 2.133 .957 & 365.443 & 4.234 .244 & $2,38 \%$ \\
\hline Norte Central & 1.954 & 2.158 .155 & 2.294 .489 & 601.872 & 5.056 .470 & $2,84 \%$ \\
\hline Norte Pioneiro & 6.611 & 1.167 .358 & 1.462 .628 & 487.884 & 3.124 .481 & $1,76 \%$ \\
\hline Centro Oriental & 275 & 650.983 & 1.752 .844 & 527.800 & 2.931 .902 & $1,65 \%$ \\
\hline Oeste & 2.576 & 4.952 .546 & 3.623 .383 & 429.665 & 9.008 .170 & $5,06 \%$ \\
\hline Sudoeste & 69 & 810.333 & 1.604 .720 & 417.181 & 2.832 .303 & $1,59 \%$ \\
\hline Centro-Sul & 1.051 & 758.332 & 1.989 .600 & 349.075 & 3.098 .058 & $1,74 \%$ \\
\hline Sudeste & 6.506 & 530.751 & 1.066 .071 & 139.556 & 1.742 .884 & $0,98 \%$ \\
\hline Metropolitana & 9.071 & 515.754 & 478.645 & 32.229 & 1.035 .699 & $0,58 \%$ \\
\hline Rio Grande do Sul & 7.493 .431 & 4.729 .948 & 16.209 .892 & 2.541 .889 & 30.975 .160 & $17,41 \%$ \\
\hline Noroeste & 29.349 & 2.688 .039 & 10.033 .224 & 2.041 .670 & 14.792 .282 & $8,32 \%$ \\
\hline Nordeste & 31 & 807.471 & 1.047 .597 & 155.394 & 2.010 .493 & $1,13 \%$ \\
\hline Centro-Ocidental & 610.903 & 165.533 & 2.075 .553 & 167.953 & 3.019 .942 & $1,70 \%$ \\
\hline Centro Oriental & 440.372 & 524.734 & 904.369 & 27.943 & 1.897 .418 & $1,07 \%$ \\
\hline Metropolitana & 1.723 .866 & 178.716 & 266.610 & 5.160 & 2.174 .352 & $1,22 \%$ \\
\hline Sudoeste & 3.116 .642 & 158.599 & 1.304 .709 & 127.599 & 4.707 .549 & $2,65 \%$ \\
\hline Sudeste & 1.572 .268 & 206.856 & 577.830 & 16.170 & 2.373 .124 & $1,33 \%$ \\
\hline Goiás & 108.194 & 5.804 .842 & 10.239 .473 & 63.461 & 16.215 .970 & $9,12 \%$ \\
\hline Noroeste & 14.340 & 51.442 & 341.104 & 0 & 406.886 & $0,23 \%$ \\
\hline Norte & 14.859 & 155.474 & 308.714 & 344 & 479.391 & $0,27 \%$ \\
\hline Centro & 7.083 & 318. & 359 & 0 & 616.037 & $0,35 \%$ \\
\hline Leste & 67.640 & 955.224 & 1.555 .246 & 56.880 & 2.634 .990 & $1,48 \%$ \\
\hline Sul & 4.272 & 4.324 .107 & 7.744 .050 & 6.237 & 12.078 .666 & $6,79 \%$ \\
\hline Mato Grosso & 501.045 & 15.339 .785 & 26.277 .303 & 0 & 42.118 .133 & $23,68 \%$ \\
\hline Norte & 459.090 & 10.717 .610 & 16.706 .487 & 0 & 27.883 .187 & $15,67 \%$ \\
\hline Nordeste & 34.656 & 1.565 .798 & 4.697 .896 & 0 & 6.298 .350 & $3,54 \%$ \\
\hline Sudoeste & 3.167 & 287.322 & 493.947 & 0 & 784.436 & $0,44 \%$ \\
\hline Centro Sul & 3.382 & 258.316 & 419.591 & 0 & 681.289 & $0,38 \%$ \\
\hline Sudeste & 750 & 2.510 .739 & 3.959 .382 & 0 & 6.470 .871 & $3,64 \%$ \\
\hline Mato Grosso do Sul & 75.871 & 6.029 .756 & 7.389 .990 & 47.720 & 13.543 .337 & $7,61 \%$ \\
\hline Pantanais & 30.617 & 55.068 & 79.039 & 175 & 164.899 & $0,09 \%$ \\
\hline Centro Norte & 1.800 & 1.550 .402 & 1.639 .641 & 2.500 & 3.194 .343 & $1,80 \%$ \\
\hline Leste Sul & 0 & 675.259 & 857.664 & 0 & 1.532 .923 & $0,86 \%$ \\
\hline Sudoeste & 43.454 & 3.749 .027 & 4.813 .646 & 45.045 & 8.651 .172 & $4,86 \%$ \\
\hline Minas Gerais & 15.283 & 5.843 .579 & 4.747 .494 & 219.436 & 10.825 .792 & $6,09 \%$ \\
\hline Noroeste & 2.343 & 824.201 & 1.661 .197 & 9.380 & 2.497 .121 & $1,40 \%$ \\
\hline Norte & 1.675 & 166.680 & 110.224 & 0 & 278.579 & $0,16 \%$ \\
\hline Jequitinhonha & 72 & 29.649 & 0 & 0 & 29.721 & $0,02 \%$ \\
\hline Vale do Mucuri & 100 & 6.172 & 0 & 0 & 6.272 & $0,00 \%$ \\
\hline Triangulo Mineiro & 374 & 2.179 .525 & 2.555 .299 & 110.084 & 4.845 .282 & $2,72 \%$ \\
\hline Central Mineira & 71 & 111.770 & 15.686 & 0 & 127.527 & $0,07 \%$ \\
\hline Metropolitana & 334 & 137.851 & 2.429 & 220 & 140.834 & $0,08 \%$ \\
\hline Vale do Rio Doce & 3.477 & 94.635 & 0 & 0 & 98.112 & $0,06 \%$ \\
\hline Oeste & 1.306 & 479.945 & 68.223 & 5.024 & 554.498 & $0,31 \%$ \\
\hline Sul e Sudoeste & 4.314 & 1.228 .267 & 255.332 & 45.355 & 1.533 .268 & $0,86 \%$ \\
\hline Campo das Vertentes & 536 & 396.577 & 79.104 & 49.373 & 525.590 & $0,30 \%$ \\
\hline Zona da Mata & 681 & 188.307 & 0 & 0 & 188.988 & $0,11 \%$ \\
\hline
\end{tabular}




\begin{tabular}{|c|c|c|c|c|c|c|}
\hline São Paulo & 60.860 & 4.592.671 & 2.791 .872 & 361.007 & 7.806 .410 & $4,39 \%$ \\
\hline São José do Rio Preto & 13 & 273.474 & 77.345 & 0 & 350.832 & $0,20 \%$ \\
\hline Ribeirão Preto & 1.016 & 339.274 & 416.511 & 0 & 756.801 & $0,43 \%$ \\
\hline Araçatuba & 0 & 188.948 & 123.523 & 0 & 312.471 & $0,18 \%$ \\
\hline Bauru & 358 & 343.127 & 197.442 & 30.573 & 571.500 & $0,32 \%$ \\
\hline Araraquara & 36 & 82.934 & 28.803 & 0 & 111.773 & $0,06 \%$ \\
\hline Piracicaba & 35 & 161.583 & 25.127 & 0 & 186.745 & $0,10 \%$ \\
\hline Campinas & 528 & 621.742 & 44.655 & 1.979 & 668.904 & $0,38 \%$ \\
\hline Presidente Prudente & 38 & 168.117 & 106.296 & 0 & 274.451 & $0,15 \%$ \\
\hline Marilia & 25 & 60.448 & 15.314 & 0 & 75.787 & $0,04 \%$ \\
\hline Assis & 3.480 & 859.003 & 681.001 & 9.977 & 1.553 .461 & $0,87 \%$ \\
\hline Itapetininga & 4.348 & 1.189 .010 & 1.013 .714 & 304.253 & 2.511 .325 & $1,41 \%$ \\
\hline Macro Metropolitana & 24 & 279.601 & 58.067 & 13.232 & 350.924 & $0,20 \%$ \\
\hline Vale do Paraíba & 42.618 & 22.508 & 4.074 & 885 & 70.085 & $0,04 \%$ \\
\hline Litoral Sul & 8.341 & 1.645 & 0 & 108 & 10.094 & $0,01 \%$ \\
\hline Demais Estados & 1.197 .645 & 5.385.367 & 9.475 .967 & 22.194 & 16.081 .173 & $9,04 \%$ \\
\hline Acre & 6.375 & 82.329 & 150 & 0 & 88.854 & $0,05 \%$ \\
\hline Alagoas & 15.249 & 12.910 & 1.043 & 0 & 29.202 & $0,02 \%$ \\
\hline Amapá & 1.312 & 1.517 & 42.351 & 0 & 45.180 & $0,03 \%$ \\
\hline Amazonas & 819 & 8.062 & 0 & 0 & 8.881 & $0,00 \%$ \\
\hline Bahia & 7.247 & 1.580 .460 & 3.257 .119 & 19.800 & 4.864 .626 & $2,73 \%$ \\
\hline Ceará & 14.373 & 114.675 & 0 & 0 & 129.048 & $0,07 \%$ \\
\hline Distrito Federal & 0 & 292.474 & 233.888 & 2.394 & 528.756 & $0,30 \%$ \\
\hline Espírito Santo & 491 & 37.897 & 0 & 0 & 38.388 & $0,02 \%$ \\
\hline Maranhão & 152.216 & 682.791 & 1.242 .772 & 0 & 2.077 .779 & $1,17 \%$ \\
\hline Pará & 181.660 & 643.008 & 1.304 .598 & 0 & 2.129 .266 & $1,20 \%$ \\
\hline Paraíba & 144 & 12.613 & 0 & 0 & 12.757 & $0,01 \%$ \\
\hline Pernambuco & 2.207 & 13.364 & 0 & 0 & 15.571 & $0,01 \%$ \\
\hline Piauí & 43.488 & 600.690 & 644.263 & 0 & 1.288 .441 & $0,72 \%$ \\
\hline Rio de Janeiro & 856 & 7.563 & 0 & 0 & 8.419 & $0,00 \%$ \\
\hline Rio Grande do Norte & 3.244 & 2.943 & 0 & 0 & 6.187 & $0,00 \%$ \\
\hline Rondônia & 138.175 & 602.411 & 759.928 & 0 & 1.500 .514 & $0,84 \%$ \\
\hline Roraima & 67.556 & 17.013 & 67.347 & 0 & 151.916 & $0,09 \%$ \\
\hline Sergipe & 33.058 & 140.962 & 0 & 0 & 174.020 & $0,10 \%$ \\
\hline Tocantins & 529.175 & 531.685 & 1.922 .508 & 0 & 2.983 .368 & $1,68 \%$ \\
\hline TOTAL & 10.622 .189 & 64.143 .414 & 96.296 .714 & 6.834 .421 & 177.896 .738 & $100 \%$ \\
\hline
\end{tabular}

Fonte: Adaptado de IBGE (2016).

Os estados do Mato Grosso, Paraná e Rio Grande do Sul configuram-se enquanto os principais produtores de grãos agrícolas do país. No Mato-Grosso, destaque para a região Norte, principalmente no que toca ao milho e à soja. No Paraná, o destaque fica com a região Oeste, principalmente na produção, também, de milho e soja. Por sua vez, no Rio Grande do Sul o destaque vai para a região Noroeste na produção de soja e trigo.

Avançando, as principais regiões produtoras agrícolas foram encontradas e ordenadas em suas 20 principais microrregiões produtoras, independente de pertencerem aos estados da federação líderes na produção ou não, ordenadas de forma decrescente pela sua produção no quadro 03.

Quadro 3 - Produção brasileira, por mesorregiões dos estados ou estados, dos principais grãos agrícolas no ano de 2016, em toneladas (t) e classificada em ordem crescente

\begin{tabular}{|c|c|c|c|c|c|c|c|c|}
\hline Posição & UF & $\begin{array}{c}\text { Mesorregião } \\
\text { ou estado }\end{array}$ & Arroz & Milho & Soja & Trigo & TOTAL & $\%$ \\
\hline $1^{a}$ & MT & Norte & 459.090 & 10.717 .610 & 16.706 .487 & 0 & 27.883 .187 & $15,67 \%$ \\
\hline $2^{a}$ & RS & Noroeste & 29.349 & 2.688 .039 & 10.033 .224 & 2.041 .670 & 14.792 .282 & $8,32 \%$ \\
\hline
\end{tabular}




\begin{tabular}{|c|c|c|c|c|c|c|c|c|}
\hline $3^{\mathrm{a}}$ & GO & Sul Goiano & 4.272 & 4.324.107 & 7.744 .050 & 6.237 & 12.078 .666 & $6,79 \%$ \\
\hline $4^{\mathrm{a}}$ & PR & Oeste & 2.576 & 4.952 .546 & 3.623 .383 & 429.665 & 9.008 .170 & $5,06 \%$ \\
\hline $5^{a}$ & MS & Sudoeste & 43.454 & 3.749 .027 & 4.813 .646 & 45.045 & 8.651 .172 & $4,86 \%$ \\
\hline $6^{a}$ & MT & Sudeste & 750 & 2.510 .739 & 3.959 .382 & 0 & 6.470 .871 & $3,64 \%$ \\
\hline $7^{a}$ & MT & Nordeste & 34.656 & 1.565 .798 & 4.697 .896 & 0 & 6.298 .350 & $3,54 \%$ \\
\hline $8^{a}$ & PR & Norte Central & 1.954 & 2.158 .155 & 2.294 .489 & 601.872 & 5.056 .470 & $2,84 \%$ \\
\hline $9^{a}$ & MG & $\begin{array}{c}\text { Triangulo } \\
\text { Mineiro }\end{array}$ & 374 & 2.179 .525 & 2.555 .299 & 110.084 & 4.845 .282 & $2,72 \%$ \\
\hline $10^{a}$ & RS & Sudoeste & 3.116 .642 & 158.599 & 1.304 .709 & 127.599 & 4.707 .549 & $2,65 \%$ \\
\hline $11^{a}$ & PR & $\begin{array}{c}\text { Centro } \\
\text { Ocidental }\end{array}$ & 283 & 1.734 .561 & 2.133 .957 & 365.443 & 4.234 .244 & $2,38 \%$ \\
\hline $12^{a}$ & MS & Centro Norte & 1.800 & 1.550 .402 & 1.639 .641 & 2.500 & 3.194 .343 & $1,80 \%$ \\
\hline $13^{a}$ & PR & $\begin{array}{c}\text { Norte } \\
\text { Pioneiro } \\
\end{array}$ & 6.611 & 1.167 .358 & 1.462 .628 & 487.884 & 3.124 .481 & $1,76 \%$ \\
\hline $14^{a}$ & PR & Centro-Sul & 1.051 & 758.332 & 1.989 .600 & 349.075 & 3.098 .058 & $1,74 \%$ \\
\hline $15^{a}$ & RS & $\begin{array}{c}\text { Centro- } \\
\text { Ocidental }\end{array}$ & 610.903 & 165.533 & 2.075 .553 & 167.953 & 3.019 .942 & $1,70 \%$ \\
\hline $16^{a}$ & PR & $\begin{array}{l}\text { Centro } \\
\text { Oriental }\end{array}$ & 275 & 650.983 & 1.752 .844 & 527.800 & 2.931 .902 & $1,65 \%$ \\
\hline $17^{a}$ & PR & Sudoeste & 69 & 810.333 & 1.604 .720 & 417.181 & 2.832 .303 & $1,59 \%$ \\
\hline $18^{a}$ & SC & Oeste & 315 & 1.521 .516 & 1.050 .827 & 116.813 & 2.689 .471 & $1,51 \%$ \\
\hline $19^{a}$ & RS & Sudeste & 1.572 .268 & 206.856 & 577.830 & 16.170 & 2.373 .124 & $1,33 \%$ \\
\hline $20^{a}$ & RS & Metropolitana & 1.723 .866 & 178.716 & 266.610 & 5.160 & 2.174 .352 & $1,22 \%$ \\
\hline $21^{a}$ & RS & Nordeste & 31 & 807.471 & 1.047 .597 & 155.394 & 2.010 .493 & $1,13 \%$ \\
\hline $22^{\mathrm{a}}$ & RS & $\begin{array}{l}\text { Centro } \\
\text { Oriental }\end{array}$ & 440.372 & 524.734 & 904.369 & 27.943 & 1.897 .418 & $1,07 \%$ \\
\hline $23^{a}$ & PR & Sudeste & 6.506 & 530.751 & 1.066 .071 & 139.556 & 1.742 .884 & $0,98 \%$ \\
\hline $24^{a}$ & $\mathrm{PR}$ & Noroeste & 90.605 & 608.330 & 618.775 & 6.744 & 1.324 .454 & $0,74 \%$ \\
\hline $25^{a}$ & $\mathrm{PR}$ & Metropolitana & 9.071 & 515.754 & 478.645 & 32.229 & 1.035 .699 & $0,58 \%$ \\
\hline $26^{a}$ & SC & Serrana & 30 & 438.441 & 543.874 & 42.673 & 1.025 .018 & $0,58 \%$ \\
\hline $27^{a}$ & SC & Norte & 143.544 & 280.224 & 504.185 & 56.274 & 984.227 & $0,55 \%$ \\
\hline $28^{a}$ & SC & $\begin{array}{c}\text { Sul } \\
\text { Catarinense }\end{array}$ & 660.677 & 99.441 & 774 & 0 & 760.892 & $0,43 \%$ \\
\hline $29^{a}$ & SC & Vale do Itajaí & 208.929 & 170.501 & 39.807 & 5.361 & 424.598 & $0,24 \%$ \\
\hline \multirow[t]{2}{*}{$30^{a}$} & OT & \begin{tabular}{|c|} 
Outras \\
Regiões \\
\end{tabular} & 1.451 .866 & 16.419 .032 & 18.805 .842 & 550.096 & 37.226 .836 & $20,93 \%$ \\
\hline & \multicolumn{2}{|r|}{ TOTAL } & 10.622 .189 & 64.143 .414 & 96.296 .714 & 6.834 .421 & 177.896 .738 & $100 \%$ \\
\hline
\end{tabular}

Fonte: Adaptado de IBGE (2016).

Nesse sentido, além das regiões já destacadas anteriormente, destaca-se o Sul goiano, o Oeste paranaense e o Sudoeste sul-mato-grossense, além de tantas outras, conforme evidenciado no quadro 03. Assim, fica nítido que as principais regiões produtoras pertencem ao eixo Sul-Centro-Oeste brasileiro.

\subsection{Distâncias rodoviárias aos principais portos brasileiros}

Finalizado a coleta dos dados referentes à produção agrícola, ou seja, tendo sido cumprido o primeiro objetivo específico da proposta, buscou-se então identificar as cidades satélites destas regiões para utilizar como referência de distância para os cálculos de transporte logístico, dando seguimento ao segundo objetivo específico do trabalho. 
As distâncias logísticas foram medidas em comparação com os principais portos do sul e sudeste brasileiro que operam os referidos produtos, quais sejam: Porto de Paranaguá (PR), Porto de São Francisco do Sul (SC), Porto de Imbituba (SC), Porto de Rio Grande e seus terminais (RS) e Porto de Santos (SP), sendo utilizada a plataforma Google Maps para a medição destas distâncias. O quadro 4 trás o compilamento referente a tais distâncias:

Quadro 4 - Distâncias rodoviárias, em quilômetros $(\mathrm{km})$, entre as principais regiões produtoras e os principais portos exportadores de grãos do Sul e Sudeste brasileiro

\begin{tabular}{|c|c|c|c|c|c|c|c|}
\hline UF & Mesorregiões & $\begin{array}{c}\text { Cidade } \\
\text { Referência }\end{array}$ & $\begin{array}{l}\text { Distância } \\
\text { até } \\
\text { Paranaguá }\end{array}$ & $\begin{array}{c}\text { Distância } \\
\text { até } \\
\text { Imbituba }\end{array}$ & \begin{tabular}{|c|} 
Distância \\
até Rio \\
Grande
\end{tabular} & $\begin{array}{l}\text { Distância } \\
\text { até S.F.S }\end{array}$ & $\begin{array}{c}\text { Distância } \\
\text { até } \\
\text { Santos }\end{array}$ \\
\hline MT & $\begin{array}{c}\text { Norte } \\
\text { Matogrossense }\end{array}$ & Sinop & 2278 & 2550 & 2853 & 2348 & 2130 \\
\hline RS & Noroeste & Erechim & 744 & 567 & 676 & 587 & 1187 \\
\hline GO & Sul Goiano & Itumbiara & 1188 & 1455 & 2150 & 1277 & 828 \\
\hline PR & Oeste & Toledo & 792 & 919 & 1039 & 714 & 1050 \\
\hline MS & Sudoeste & Dourados & 966 & 1238 & 1453 & 1022 & 1159 \\
\hline MT & Sudeste & $\begin{array}{c}\text { Tangará da } \\
\text { Serra }\end{array}$ & 2183 & 2315 & 2986 & 2183 & 2012 \\
\hline MT & Nordeste & Canarana & 1915 & 2187 & 2858 & 2162 & 1757 \\
\hline PR & Norte Central & Maringá & 655 & 818 & 1329 & 725 & 813 \\
\hline MG & $\begin{array}{c}\text { Triangulo } \\
\text { Mineiro }\end{array}$ & Uberlândia & 1039 & 1330 & 2001 & 1128 & 669 \\
\hline RS & Sudoeste & Bagé & 1173 & 743 & 235 & 1153 & 1592 \\
\hline PR & $\begin{array}{c}\text { Centro } \\
\text { Ocidental }\end{array}$ & $\begin{array}{l}\text { Campo } \\
\text { Mourão }\end{array}$ & 610 & 823 & 1231 & 625 & 822 \\
\hline MS & Centro Norte & $\begin{array}{l}\text { Campo } \\
\text { Grande }\end{array}$ & 1143 & 1360 & 1628 & 1170 & 1094 \\
\hline PR & Norte Pioneiro & $\begin{array}{l}\text { Cornélio } \\
\text { Procópio }\end{array}$ & 603 & 894 & 1442 & 692 & 559 \\
\hline PR & Centro-Sul & Guarapuava & 363 & 635 & 1027 & 475 & 840 \\
\hline RS & $\begin{array}{c}\text { Centro- } \\
\text { Ocidental } \\
\end{array}$ & Santa Maria & 909 & 654 & 444 & 938 & 1258 \\
\hline PR & Centro Oriental & Ponta Grossa & 250 & 487 & 1157 & 320 & 600 \\
\hline PR & Sudoeste & \begin{tabular}{|c|}
$\begin{array}{c}\text { Francisco } \\
\text { Beltrão }\end{array}$ \\
\end{tabular} & 700 & 706 & 921 & 670 & 898 \\
\hline SC & Oeste & Chapecó & 673 & 667 & 756 & 589 & 876 \\
\hline RS & Sudeste & Pelotas & 1040 & 610 & 77 & 1082 & 1360 \\
\hline RS & Metropolitana & $\begin{array}{c}\text { São } \\
\text { Leopoldo }\end{array}$ & 821 & 391 & 428 & 391 & 855 \\
\hline RS & Nordeste & $\begin{array}{c}\text { Caxias do } \\
\text { Sul }\end{array}$ & 921 & 380 & 527 & 640 & 1224 \\
\hline RS & Centro Oriental & $\begin{array}{c}\text { Santa Cruz } \\
\text { do Sul }\end{array}$ & 882 & 542 & 449 & 805 & 1342 \\
\hline PR & Sudeste & Prudentópolis & 327 & 590 & 1058 & 397 & 782 \\
\hline PR & Noroeste & Cianorte & 618 & 886 & 1265 & 684 & 820 \\
\hline PR & Metropolitana & Campo Largo & 132 & 402 & 1073 & 200 & 522 \\
\hline SC & Serrana & Lages & 586 & 276 & 738 & 391 & 762 \\
\hline SC & Norte & Mafra & 208 & 378 & 1014 & 176 & 517 \\
\hline
\end{tabular}

Fonte: Google Maps, (2018).

Diante das informações obtidas, nota-se que o Norte mato-grossense, principal região produtora de grãos do país possui como porto escoador mais próximo o de Santos/SP, porém com distância próxima nos demais portos da região sul, já o Noroeste do Rio Grande Sul possui como destino mais próximo para exportação de grãos agrícolas o Porto de Imbituba em Santa Catarina. 


\subsection{Custos logísticos de transporte por tonelada de grãos}

Após realizada as coletas de dados de distância rodoviária aos portos e sua produção agrícola, torna-se necessário identificar o custo logístico para transportar estas cargas, ou seja, dando seguimento ao terceiro objetivo específico da proposta.

A premissa utilizada para o cálculo do transporte levou em consideração o custo médio por tonelada do transporte, utilizando como base um veículo de 7 Eixos com capacidade para transporte de até 57 Toneladas, conforme normas da Agência Nacional de Transportes Terrestres, veículo este utilizado com frequência para este tipo de carga.

Diante desse aspecto, o valor de referência foi calculado tendo em vista o valor do frete mínimo publicado pela Agência Nacional de Transportes Terrestres ANTT, através da Resolução $n^{\circ} 5.820$ de 30 de Maio de 2018. Apresenta-se a seguir, por meio do quadro 05 , o custo médio por tonelada transportadas da origem aos principais portos exportadores de grãos no Brasil.

Quadro 5 - Custo médio, em reais $(R \$)$ por tonelada $(t)$, no transporte rodoviário das regiões produtoras até os principais portos exportadores de grãos do Sul e Sudeste brasileiro em 2018

\begin{tabular}{|c|c|c|c|c|c|c|}
\hline UF & Local & $\begin{array}{l}\text { Custo Até } \\
\text { Paranaguá }\end{array}$ & $\begin{array}{c}\text { Custo } \\
\text { Até } \\
\text { Imbituba }\end{array}$ & $\begin{array}{c}\text { Custo Até } \\
\text { Rio } \\
\text { Grande }\end{array}$ & $\begin{array}{c}\text { Custo } \\
\text { Até } \\
\text { SFS }\end{array}$ & $\begin{array}{c}\text { Custo } \\
\text { Até } \\
\text { Santos }\end{array}$ \\
\hline MT & Norte Matogrossense & 227,68 & 252,03 & 281,98 & 232,07 & 212,89 \\
\hline RS & Noroeste & 78,49 & 61,71 & 72,07 & 63,88 & 121,27 \\
\hline GO & Sul Goiano & 121,38 & 147,04 & 214,89 & 130,47 & 86,43 \\
\hline PR & Oeste & 83,56 & 94,91 & 107,31 & 75,33 & 108,44 \\
\hline MS & Sudoeste & 99,77 & 125,11 & 146,84 & 105,55 & 118,41 \\
\hline MT & Sudeste & 218,19 & 228,81 & 295,13 & 218,19 & 201,09 \\
\hline MT & Nordeste & 191,40 & 218,58 & 285,65 & 216,09 & 175,61 \\
\hline PR & Norte Central & 69,83 & 85,39 & 134,31 & 76,49 & 84,87 \\
\hline MG & Triangulo Mineiro & 107,31 & 134,41 & 199,99 & 115,25 & 71,32 \\
\hline RS & Sudoeste & 119,84 & 78,39 & 28,97 & 117,80 & 159,12 \\
\hline PR & Centro Ocidental & 65,03 & 85,91 & 125,77 & 66,63 & 85,81 \\
\hline MS & Centro Norte & 116,78 & 137,44 & 162,71 & 119,54 & 112,99 \\
\hline PR & Norte Pioneiro & 65,63 & 93,32 & 145,73 & 73,77 & 60,84 \\
\hline PR & Centro-Sul & 41,92 & 67,70 & 106,07 & 52,75 & 87,69 \\
\hline RS & Centro-Ocidental & 93,88 & 69,72 & 49,31 & 96,88 & 128,53 \\
\hline PR & Centro Oriental & 30,82 & 54,08 & 118,21 & 36,96 & 63,97 \\
\hline PR & Sudoeste & 73,85 & 74,48 & 95,12 & 71,43 & 93,74 \\
\hline SC & Oeste & 71,75 & 70,37 & 79,76 & 64,10 & 91,45 \\
\hline $\mathrm{RS}$ & Sudeste & 107,41 & 64,36 & 17,53 & 111,75 & 137,44 \\
\hline RS & Metropolitana & 85,70 & 45,16 & 47,53 & 45,16 & 89,25 \\
\hline $\mathrm{RS}$ & Nordeste & 95,12 & 43,89 & 57,35 & 68,23 & 123,69 \\
\hline RS & Centro Oriental & 92,07 & 58,99 & 49,86 & 84,03 & 135,62 \\
\hline PR & Sudeste & 37,77 & 64,21 & 109,27 & 45,85 & 82,50 \\
\hline PR & Noroeste & 65,89 & 92,49 & 129,24 & 72,92 & 85,60 \\
\hline PR & Metropolitana & 18,62 & 44,64 & 110,82 & 28,21 & 56,81 \\
\hline SC & Serrana & 63,78 & 34,02 & 77,86 & 45,16 & 80,39 \\
\hline SC & Norte & 25,64 & 43,66 & 104,72 & 24,82 & 56,27 \\
\hline
\end{tabular}


Fonte: Elaborado pelo autor (2018).

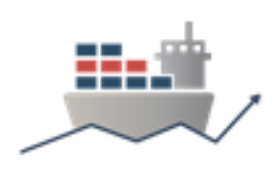

Extraída as informações de custo logístico por tonelada movimentada de grãos agrícolas foi possível identificar que o custo rodoviário com menor valor para a região norte mato-grossense é em Santos custando $R \$ 212,89$ (Duzentos e doze reais e oitenta e nove centavos), já para o Noroeste do Rio Grande do Sul, o porto mais vantajoso se torna em Imbituba, representando um custo de $\mathrm{R} \$ 61,71$ (Sessenta e um reais e setenta e um centavos) por cada tonelada transportada.

\subsection{Embarque de grãos nos principais portos e terminais brasileiros exportadores de grãos}

Com o intuito de enriquecer e complementar a pesquisa, buscou-se identificar a movimentação de grãos agrícolas registrada nos portos comparados no mesmo ano da pesquisa, assim como seus elementos de produtividade e agilidade em cada um destes portos, de modo a evidenciar se as escolhas logísticas se pautam no custo rodoviário da carga. Esta tratativa vai além dos objetivos específicos trazidos e abre portas para um aprofundamento maior dos temas e questões aqui trazidas. Deste modo, os resultados referente ao embarque de grãos agrícolas, em toneladas (t) em 2016, são os seguintes:

Quadro 6 - Embarque de grãos agrícolas, em toneladas (t), nos principais portos e terminais brasileiros exportadores de grãos em 2016

\begin{tabular}{|c|c|c|c|c|c|c|}
\hline UF & Porto de Origem & Soja & Milho & Arroz & Trigo & Total \\
\hline SC & Imbituba & 1.059 .728 & 471.335 & 0 & 148.088 & 1.679 .151 \\
\hline PR & Paranaguá & 7.950 .086 & 2.589 .878 & 0 & 0 & 10.539 .964 \\
\hline SC & São Francisco do Sul & 4.041 .420 & 984.564 & 0 & 81.398 & 5.107 .382 \\
\hline RS & Rio Grande do Sul & 4.421 .820 & 241.064 & 442.278 & 718.736 & 5.823 .898 \\
\hline SP & Santos & 13.233 .688 & 7.861 .635 & 0 & 0 & 21.095 .323 \\
\hline RS & Terminal Bianchini & 2.301 .307 & 61.602 & 54.480 & 57.737 & 2.475 .126 \\
\hline RS & Terminal Luiz & 1.722 .419 & 0 & 0 & 0 & 1.722 .419 \\
\hline MAgliatto & Itaqui & 4.002 .774 & 638.860 & 0 & 0 & 4.641 .634 \\
\hline ES & Terminal Tubarão & 2.843 .325 & 1.775 .274 & 0 & 0 & 4.618 .599 \\
\hline RS & Terminal Bunge & 1.122 .805 & 0 & 0 & 0 & 1.122 .805 \\
\hline OT & Outros Portos & 14.269 .258 & 4.407 .663 & 11.526 & 22.905 & 18.711 .352 \\
\hline
\end{tabular}

Fonte: Adaptado de ANTAQ (2016).

É possível observar que o maior exportador de grãos agrícolas atualmente no país é o Porto de Santos com aproximadamente 21 Milhões de toneladas anuais, seguida do Porto de Paranaguá com cerca de 10 Milhões de Toneladas anuais. Os terminais e portos localizados no Estado do Rio Grande do Sul embarcaram cerca de 11 Milhões de toneladas de grãos agrícolas no ano de 2016.

\subsection{Agilidade na movimentação de grãos nos portos}

Foram então observados os números referentes ao embarque dos grãos agrícolas utilizados nesta pesquisa nos Portos da região Sul e Santos/SP no ano de 2016, analisando a Prancha Média Diária (PMD), Tempo Atracado no Porto (TA), Tempo de Espera em Área de Fundeio dos Navios (T.E) e Tempo Total (TT) acostado e atracado. 
Tais números servem para evidenciar as principais agilidades e aspectos de custo da embarcação no terminal portuário, visto que quanto mais tempo de operação, maior será o custo para exportar o referido grão. Os números médios, extraídos do documento "Anuário" publicado mensalmente pela Agência Nacional de Transportes Aquaviários são transcritos abaixo:

Quadro 7 - Produtividade no embarque de grãos, em 2016, dos principais portos e terminais brasileiros exportadores de grãos.

\begin{tabular}{|c|c|c|c|c|c|c|c|c|}
\hline UF & Porto de Origem & $\begin{array}{c}\text { Embarcado } \\
(\mathbf{t})\end{array}$ & Navios & $\begin{array}{c}\text { Média } \\
\text { por } \\
\text { Navio (t) }\end{array}$ & PMD & TA & TE & TT \\
\hline SC & Imbituba & 1.679 .151 & 49 & 34.185 & 7.829 & 104,8 & 112,8 & 217,6 \\
\hline PR & Paranaguá & 10.539 .964 & 191 & 55.209 & 18.454 & 71,8 & 852,0 & 923,8 \\
\hline SC & São Francisco do Sul & 5.107 .382 & 88 & 57.735 & 21.787 & 63,6 & 259,0 & 322,6 \\
\hline RS & Rio Grande do Sul & 5.823 .898 & 94 & 62.279 & 18.731 & 79,8 & 171,5 & 251,3 \\
\hline SP & Santos & 21.095 .323 & 355 & 59.344 & 18.940 & 75,2 & 215,3 & 290,5 \\
\hline RS & Terminal Bianchini & 2.475 .126 & 41 & 60.561 & 27.476 & 52,9 & 156,1 & 209,0 \\
\hline RS & Terminal Luiz F. & 1.722 .419 & 29 & 59.394 & 12.604 & 113,1 & 317,4 & 430,5 \\
\hline MA & Itaqui Maranhão & 4.641 .634 & 79 & 58.864 & 21.054 & 67,1 & 5,3 & 72,4 \\
\hline ES & Terminal Tubarão & 4.618 .599 & 81 & 56.866 & 28.140 & 48,5 & 402,9 & 451,4 \\
\hline RS & Terminal Bunge & 1.122 .805 & 22 & 51.037 & 14.031 & 87,3 & 178,8 & 266,1 \\
\hline OT & Outros Portos & 18.711 .352 & - & - & - & - & - & - \\
\hline \multicolumn{2}{|c|}{ TOTAL } & $\mathbf{7 7 . 5 3 7 . 6 5 3}$ & & & & & & \\
\hline
\end{tabular}

Fonte: Adaptado de ANTAQ (2016).

Com as informas extraídas acima, é possível observar que o Terminal Tubarão no estado do Espirito Santos possui a melhor Prancha Média de Embarque de grãos agrícolas, com cerca de 28 Mil toneladas médias diárias embarcadas, mantendo também o menor tempo atracado de um navio com aproximadamente 48 horas para sua operação, entretanto registrando um dos maiores níveis em tempo de espera para atracação das embarcações, com cerca de 400 horas de espera.

O Porto com menor tempo de espera foi de Itaqui no Maranhão com aproximadamente 5 Horas de espera, seguido pelo Porto de Imbituba com cerca de 112 Horas de espera para atracação dos navios.

Como resultado, a pesquisa identificou que as principais regiões produtoras de grãos agrícolas são o Norte Mato-grossense e Noroeste Gaúcho, concluindo que o menor custo logístico rodoviário para transportar as mercadorias do noroeste gaúcho foi ao Porto de Imbituba em Santa Catarina. Já para o Norte Mato-grossense é o Porto de Santos (SP).

Nota-se ainda que o Noroeste Gaúcho, sendo a segunda maior região produtora de grãos do país possui um diferencial competitivo de custo logístico terrestre se comparar ao Norte Mato-grossense que possui uma distância significativa para embarque de mercadorias ao seu porto mais próximo. Sugere-se como pesquisa futura, buscar identificar os custos do afretamento marítimo em cada porto identificado, de modo que se possa concluir o custo total da cadeia logística.

\section{CONCLUSÕES}


A presente pesquisa teve como objetivo geral contabilizar o custo logístico médio no transporte rodoviário entre as regiões produtoras e os principais portos e terminais exportadores de grãos agrícolas do Sul e Sudeste do Brasil.

Para tanto, levantou-se a produção de grãos agrícolas no Brasil em escala nacional, estadual e mesorregional; identificaram-se as distâncias rodoviárias entre as principais regiões produtoras e os principais portos exportadores de grãos agrícolas das regiões Sul e Sudeste e calculou-se o custo logístico médio no transporte rodoviário entre as regiões produtoras e os principais portos exportadores de grãos do Sul e Sudeste. Além disso, com o intuito de qualificar o trabalho e abrir caminhos para outras abordagens, também se elucidou o embarque de grãos agrícolas nos principais portos e terminais brasileiros exportadores de grãos e mediu-se a produtividade destes portos no tocante ao referido serviço.

Concluiu-se, assim, que a presente pesquisa foi limitada a contabilização do custo logístico rodoviário se constitui enquanto uma etapa de um processo maior de contabilização dos custos logísticos totais que, se estudados conjuntamente a outras macrovariáveis impactantes no processo de tomada da decisão de movimentar por este ou aquele porto ou terminal de uso privado, podem assumir destacada importância, sendo fundamental sua análise para maximização dos resultados do negócio.

Como recomendação para futuras pesquisas, recomenda-se a complementação deste estudo ao analisar as demais variáveis absorvidas no custo logístico de transporte de grãos agrícolas, como a armazenagem e os custos portuários para escoamento da produção agrícola.

\section{REFERÊNCIAS}

ANTAQ - Agência Nacional de Transportes Aquaviários. Estatístico aquaviário. Disponível em: <http://web.antaq.gov.br/Anuario/>. Acesso em: 25 ago. 2018.

ANTT - Agência Nacional de Transportes Terrestres. Resolução $n^{\circ} 5.820$. Disponível em: <http://www.antt.gov.br/salalmprensa/noticias/arquivos/2018/05/ ANTT_publica_tabela_de_frete.html>. Acesso em: 30 ago. 2018.

BALLOU, R. H. Gerenciamento da cadeia de suprimentos/logística empresarial. Porto Alegre: Bookman, 2006.

BATALHA, M. O. et al. Gestão Agroindustrial. Atlas: São Paulo, 1997.

CAIXETA FILHO, J. V.; MARTINS, R. S. Gestão Logística do Transporte de Cargas. São Paulo: Atlas, 2001.

CHERNIJ, C. Solução para os gargalos. Revista Exame (Guia Exame). p.25-27, 2005.

CORREA, V. H. C. e RAMOS, P. A Precariedade do Transporte Rodoviário Brasileiro para o Escoamento da Produção de Soja do Centro-Oeste: situação e perspectivas. RESR, Piracicaba, v. 48, n. 2, p. 447-472, abr./jun. 2010.

FLORENTINO, Mauro Silva. Gestão de custo no transporte marítimo de cargas no Brasil. 2010 
GOOGLE. Como Chegar. Disponível em: <https://www.google.com.br/maps/>. Acesso em: 25 ago. 2018.

IBGE - Instituto Brasileiro de Geografia e Estatística. Produção agrícola municipal. Disponível em: <https://www.ibge.gov.br/estatisticas-novoportal/economicas/ agricultura-e pecuaria/9117-producao-agricola-municipal-culturas-temporarias-epermanentes.html?=\&t=o-que-e>. Acesso em: 25 ago. 2018.

KEEDI, S. Logística de transporte internacional: veículo prático de competitividade. 1. ed. São Paulo: Aduaneiras, 2001.

MARTINS, Eliseu. Contabilidade de Custos. São Paulo, Atlas, 2018.

MINERVINI, Nicola. O exportador: ferramentas para atuar com sucesso no mercado internacional. São Paulo: Pearson Prentice Hall, 2008.

OMETTO, J. G. S. Os gargalos da agroindústria. O Estado de São Paulo, 22 de maio 2006.

PONTES, H.L.P, CARMO, B.B.T, PORTO, A.J.V. Problemas logísticos na exportação brasileira da soja em grão. Revista Eletrônica Sistemas e Gestão, Agosto, 2008.

PADUAN, R. Cadê o dinheiro das PPPs?. Revista Exame, Ed. 843, n.39, p.36-38, 2005.

REIS, J. D. D. et al. Custo Ótimo de Transporte Rodoviário das Principais Regiões Produtoras de Soja aos Principais Portos do Brasil. SOBER - XLVI Congresso da Sociedade Brasileira de Economia, Administração e Sociologia Rural, Rio Branco, 20 jul. 2008, p. 1-21.

VERGARA, S. C. Projetos e relatórios de pesquisa em administração. 3. ed. São Paulo: Atlas, 2000. 